\title{
Therapeutic and educational objectives in Robot Assisted Play for children with autism
}

\author{
Ester Ferrari, Ben Robins, Kerstin Dautenhahn
}

\begin{abstract}
This article is a methodological paper that describes the therapeutic and educational objectives that were identified during the design process of a robot aimed at robot assisted play. The work described in this paper is part of the IROMEC project (Interactive Robotic Social Mediators as Companions) that recognizes the important role of play in child development and targets children who are prevented from or inhibited in playing. The project investigates the role of an interactive, autonomous robotic toy in therapy and education for children with special needs. This paper specifically addresses the therapeutic and educational objectives related to children with autism. In recent years, robots have already been used to teach basic social interaction skills to children with autism. The added value of the IROMEC robot is that play scenarios have been developed taking children's specific strengths and needs into consideration and covering a wide range of objectives in children's development areas (sensory, communicational and interaction, motor, cognitive and social and emotional). The paper describes children's developmental areas and illustrates how different experiences and interactions with the IROMEC robot are designed to target objectives in these areas.
\end{abstract}

\section{INTRODUCTION}

$\mathrm{T}$ HE IROMEC project (Interactive Robotic Social Mediators as Companions) [1] recognizes the important role of play in child development and targets children with autism, children with mild mental retardation, and children with severe motor impairment.

Play activity has a crucial role in a child's development process and it is the main vehicle through which children can learn about themselves and their environments as well as develop social skills.

Theorists from different viewpoints agree that play is an essential activity during childhood, and that its absence provides an obstacle to the development of a healthy child [2-5]. The importance of play for children's development has also been recognized by the United Nations High Commission for Human Rights [6] as a right of every child. Impairments in cognitive, developmental, or physical domains affect children's playing skills and leads to general impairments in their learning potential in addition to

The work described in this paper is conducted within the EU project IROMEC (Interactive Robotic Social Mediators as Companions) and was funded by the European Commission in the 6th Framework Programme under contract IST-FP6-045356.

E. Ferrari, B. Robins and K. Dautenhahn are with the Adaptive Systems Research Group. School of Computer Science, University of Hertfordshire, UK (email: \{e.ferrari, b.robins, k.dautenhahn\} @ herts.ac.uk) resulting in their isolation from their social environments.

For children with special needs play can be a difficult experience, as they might have limited access to this activity and may show subsequent problems in skill acquisition in various developmental areas. However, their cognitive and social development can be improved by giving them the same play opportunities as their typically-developing peers. In order to do so, it is important to provide them with the right stimuli for their developmental levels, strengths and needs. In that sense, robotic systems can be a valuable tool for children with special needs to learn through play interactions and can help them to reach the developmental steps of their chronological and/or mental ages [7].

In recent years there have been many examples of robots being used to involve children with special needs in play activities for therapeutic or educational purposes. Robots can provide a safe and predictable playful environment for children with autism to enjoy and interact with [34]. Research has shown that robots can provide a focus of attention [8] and promote spontaneous play in children with developmental disorders [9]. Remotely controlled robotic systems [10], artificial pets such as the baby seal Paro [1112], the teddy bear Huggable [13], small, simple creaturelike such as the robot Keepon [9], humanoid robots such as the robotic doll Robota [14-16], the humanoid structure on wheels Tito [17] and the child-like Kaspar [18] have been used to engage children in playful interactions and helped them in developing social skills. The added value of the IROMEC robot is that play scenarios have been developed which take children's specific strengths and needs into consideration and cover different objectives in five different developmental areas (sensory, communicational and interaction, motor, cognitive and social and emotional). Note, the IROMEC robot operates autonomously once a particular play scenario has been selected. Moreover, it covers play needs of children with a variety of special needs (e.g. cognitive impairments, physical impairments, development impairments). This aspect is quite important because often children with special needs are affected with profound and multiple disabilities. The paper describes the therapeutic and educational objectives of the IROMEC play scenarios targeting only children with autism.

\section{A. Children with autism}

In recent years, the number of children diagnosed with autism has increased. It is estimated that there are up to two 
cases of ASD (Autistic Spectrum Disorders) per thousand children [19]. Autism is a developmental disorder characterized by impairments in communication, social interaction, and imagination [20] that can occur to different degrees and in a variety of forms [21]. Children with autism often have accompanying learning disabilities ${ }^{1}$. The exact cause or causes of autism is/are still unknown.

Children with autism often experience an inability to relate to other people, little use of eye contact, difficulty in verbal and non-verbal communication, and tendencies toward repetitive behaviour patterns [22]. In addition some of them might have hyper-sensitive sensory conditions (e.g. touch can be excruciating, smell can be overpowering, sound even at an average volume can hurt, and sight can be distorted) [23].

Resources for children with autism and their families are usually rare and costly. Therefore, a robot that could help them to learn and acquire new developmental skills while having fun would be appreciated by teachers and parents as well as enriching for the children.

\section{IROMEC ROBOTIC SOCIAL MEDIATOR}

The IROMEC robotic toy can play a therapeutic role for children with autism by encouraging the development of communication, motor, cognitive, sensory and social interaction skills towards joyful experiences in interactive play. It provides those children with new opportunities for playing and learning in addition to supporting the enhancement of their potential.

The development process of the IROMEC robot is based on a user-centred perspective. Ongoing consultations with panels of experts have been conducted throughout all design stages to collect important information related to the play activity of children with special needs. The panels involved professionals from different special education schools, teachers, therapists (e.g. psychotherapists, speech therapists, play therapists, physiotherapists, occupational therapists), as well as parents and family members. Details on the role of user panels in this design process can be found in [37-38]. They informed the design process about the children's likes, dislikes, abilities and needs, and the ways they envisage the use of robotic toys in therapy or education. Given the nature of the children's impairments, they were not directly included in user panels process; instead, the involvement of the children occurred during exploratory studies where specific design aspects were tested.

Users of the IROMEC robot are not only children with autism that play with it, but also their teachers or parents, who will either be part of the play activity or simply set up the scenario for play with the robot without necessarily being

\footnotetext{
${ }^{1}$ For detailed diagnostic criteria the reader is referred to DSM-IV-TR, the Diagnostic and Statistical Manual of Mental Disorders, American Psychiatric Association, (2000) and ICD-10, Classification of Mental and Behavioural Disorders, World Health Organisation, Geneva (1993).
}

involved in the game. Note, the robot operates autonomously in the interactive play scenarios with the children and possibly other participants.

A major challenge in robot assisted play for children with autism is that such children can be very different one from another and experience many different idiosyncrasies of various scales. In addition to having different needs, they might also show completely different patterns of behaviour or some contradictory needs. In light of this, the IROMEC robot has been developed as a system that can be efficiently tailored to the users' needs. A specific feature of the robotic toy is that it can be adapted to various play scenarios by being modular in terms of software (for activation of different behaviours) and hardware (by attaching different interaction modules). The robot allows the use of different inputs (e.g. direct operation on touch screen, buttons, remotely controlled switches, etc.) which can be changed according to children's abilities and provides personalized feedback according to child's and therapist's preferences. Moreover, the robot can adjust over time by gradually increasing the complexity of the scenario played. In this way, children can find the game stable and predictable enough to feel comfortable in playing with the robot, and at the same time, small variations will help them improve in different developmental areas.

The IROMEC robot [36] has two different configuration possibilities: horizontal and vertical. In the horizontal configuration (see fig. 1) the interaction module is attached to the mobile platform in order to support a complete set of activities requiring a wider mobility and dynamism of the robot. In the vertical configuration the interaction module is connected to a dedicated docking station to provide both stability and recharging. Additionally, the robot has several interfaces such as dynamic screens for input and output, buttons and wireless switches. In order to satisfy the needs of children with autism, the robot is also equipped with a simple mask to cover the small face screen.

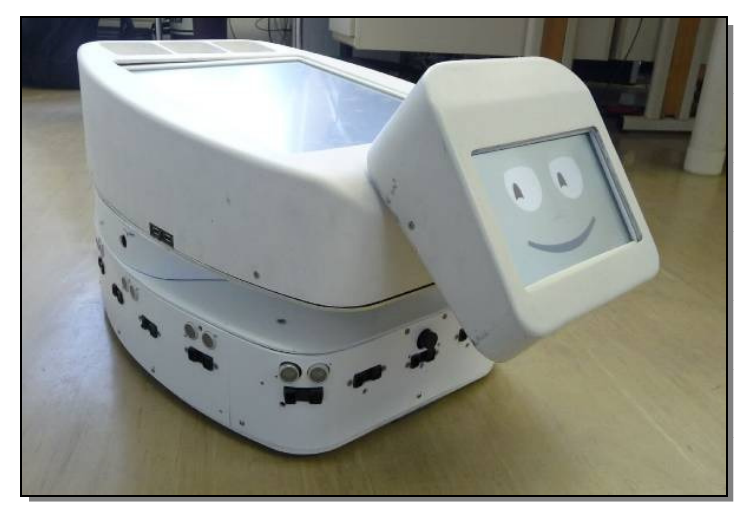

Fig. 1. The IROMEC robot in the horizontal configuration (early prototype version).

\section{A. Scenarios for Robot Assisted Play}

Ten play scenarios for robot assisted play and robotic mediator have been developed (see fig. 2), adopting the 
ESAR system [24] that identifies four different types of play $^{2}$. These types of play help children to socialize by teaching them how to take turns, observe rules, and respect the opinions and actions of fellow players. Moreover, they have a vital role in learning different types of knowledge and skills, and helping to develop basic interaction functions, memory, attention, communication functions, perceptual and motor skills.

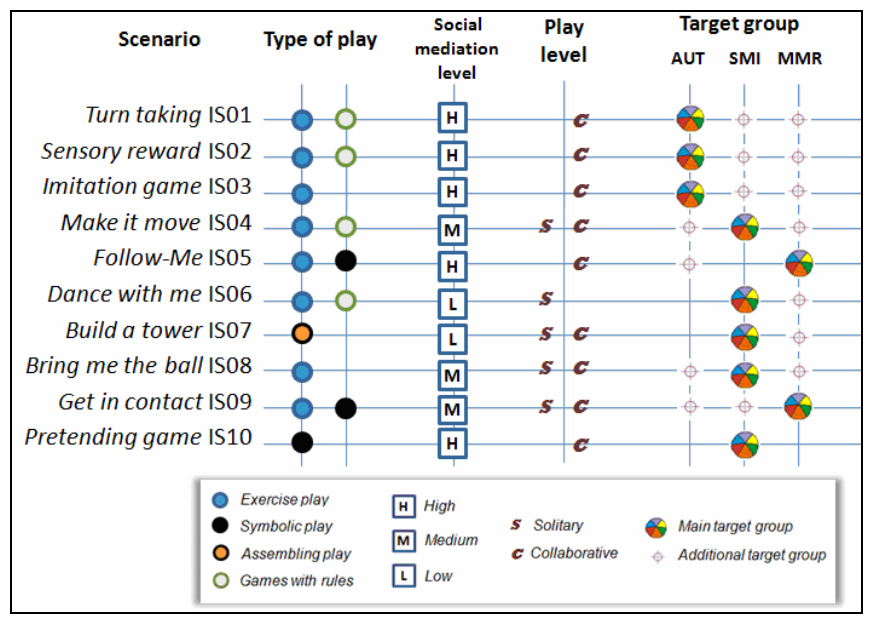

Fig. 2. IROMEC robot assisted play scenarios

The IROMEC scenarios ${ }^{3}$ have the form of textual narratives describing an activity in its context. Their structure has been adopted and modified from the scenario based design methodology [27-29] and consists of the description of actors and their roles, the type of play, the description of the activity, the recursive model, the place and setting, the artifact used, and the duration of the activity.

In particular, the play scenarios have been developed based on an extended literature review related to existing technology used in play activities, as well as information from the users panels regarding play activities, limitations, needs, and the range of interactions that robotic devices can facilitate. While an extensive literature review can provide an important starting point for the development of scenarios, the opinions of and feedback from experts were a crucial source of information. Details of the scenario development process can be found in [25].

Various aspects of the user requirements were implemented in experimental play scenarios and investigated in field trials using existing available technology. Existing robotic platforms have been used with children with autism to test out different aspects of a preliminary set of play scenarios, and in collaboration with the experts, this set has been further developed against specific therapeutic and educational objectives. The final 10 IROMEC Scenarios (IS) reflect and utilise the specific functionalities implemented in

\footnotetext{
${ }^{2}$ The four types of play are: exercise play, assembling play, symbolic play, and games with rules.

${ }^{3}$ For detailed information on the IROMEC scenarios and on their developmental process see [25-26]
}

the IROMEC robot and its various modules.

For each scenario, a comprehensive set of therapeutic and educational objectives has been drawn on, working in a closed loop with both therapists and teachers. These objectives have been developed according to the ICF-CY classification (International Classification of Functioning, Disability and Health for Children and Youth) [30].

\section{THERAPEUTIC AND EDUCATIONAL OBJECTIVES TARGETING CHILDREN WITH AUTISM}

Although the term therapy implies some form of correction to restore normal function, in the field of special education it has a much wider connotation. Here, therapy applies not only to the deficit needs created by the children's impaired conditions, but also to their growth needs. In doing so it overlaps and contributes to education to a considerable extent. The concept of education refers to the process of helping children in development and growth, giving them skills that they will use throughout life.

For children with special needs, education and therapy are combined together. It is only through a program in which the educational and the therapeutic approach are integrated and tailored to the needs of the individual child that the child's physical, mental and social development can be achieved.

As the IROMEC robot has been developed through considering the child as a whole as well as identifying the child's specific strengths and needs, it can also be used in educational and therapeutic interventions. The play scenarios cover all the important domains of children's development that are: intellectual, sensory, communicational, motor, social and emotional development [31].

IROMEC's educational and therapeutic objectives focus on reducing children's limitations by taking advantage of their strengths. Children with autism often experience high levels of discomfort when interacting with people or in unpredictable environments, while they enjoy interactions with robots. The IROMEC robot can provide a less threatening environment for interactions thanks to its predictable and repetitive nature. Utilizing children's preferences for predictable environments, the IROMEC robot can act as a social mediator, facilitating children's interactions with peers and adults. Once a "safe" environment has been established for the child, the interaction can be gently moved from a dyadic (child-robot) interaction towards a triadic (child-robot-other human, where the other human can be a peer, a family member, a therapist or a teacher) interaction.

Most importantly, the IROMEC robot is not meant to replace teachers or therapists; it is simply a tool for social mediation. The robotic toy is intended to be used as a scaffolding element [15] during child development by encouraging children to discover a range of play styles, from solitary to social and cooperative play.

The IROMEC robot offers to the children different play 
scenarios which provide a variety of experiences and possibilities for developing aspects in all the developmental domains.

The following sections describe the specific IROMEC objectives in the five different developmental areas (sensory development, communication and interaction, cognitive development, motor development and social and emotional development) considering only the scenarios targeting children with autism (see fig. 3).

\begin{tabular}{|c|c|c|c|c|c|c|c|}
\hline Sensory development & 1501 & 1502 & $\mathbf{E} 0 \mathbf{3}$ & BS04 & $\mathbf{1 5 0 5}$ & IS08 & B 09 \\
\hline Perceptual functions & 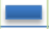 & $\square$ & 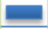 & 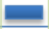 & - & $\square$ & 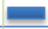 \\
\hline \multicolumn{8}{|l|}{ Communication and interaction } \\
\hline $\begin{array}{l}\text { Voice and speech functions } \\
\text { Communicating - Producing - Speaking } \\
\text { Communicating - Producing - Pretalking } \\
\text { Communicating - Producing - nonverbal } \\
\text { Basic interpersonal interaction } \\
\text { Particular interpersonal relationships }\end{array}$ & 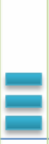 & 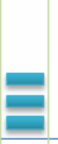 & 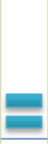 & 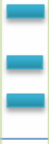 & 0 & $\square$ & 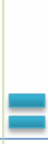 \\
\hline \multicolumn{8}{|l|}{ Cognitive development } \\
\hline $\begin{array}{l}\text { Global intellectual functions } \\
\text { Memory functions } \\
\text { Higher-level cognitive functions } \\
\text { Thinking } \\
\text { Solving problems } \\
\text { Making decisions } \\
\text { Copying } \\
\text { Attention } \\
\text { Energy and drive functions } \\
\text { Learning through action with objects } \\
\text { Undertaking single/multiple task }\end{array}$ & 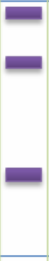 & 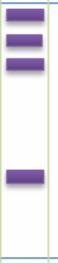 & 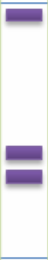 & $=$ & 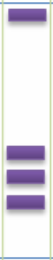 & 0 & 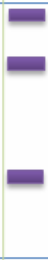 \\
\hline \multicolumn{8}{|l|}{ Social, and emotional development } \\
\hline $\begin{array}{l}\text { Emotional functions } \\
\text { Experience of self and others } \\
\text { Engagement in play } \\
\text { Community social and civic life }\end{array}$ & 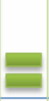 & 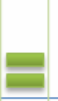 & 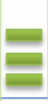 & 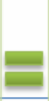 & 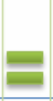 & 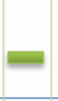 & $\Xi$ \\
\hline \multicolumn{8}{|l|}{ Motor development } \\
\hline $\begin{array}{l}\text { Mobility (body) } \\
\text { Mobility (objects) } \\
\text { Mobility (fine hand use) } \\
\text { Neuromusculoskelatal functions } \\
\text { Psychomotor functions }\end{array}$ & $\square$ & 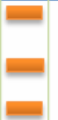 & 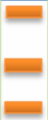 & $=$ & $\equiv$ & $\square$ & \\
\hline
\end{tabular}

Fig. 3. IROMEC objectives for children with autism, allocated to the children's five developmental areas. Only scenarios related to autism are listed (IS01-IS05, IS08, IS09).

\section{A. Sensory development}

Sensory perception provides the information on which the children base their understanding of the surroundings and which guides their responses to the environment. Toys that give sensory stimulation are of great significance for children with special needs.

For some children with autism, sensory stimulation can be the only way to motivate the child to interact.

In the play scenarios with the IROMEC robot, sensory development includes different elements such as visual perception, tactile perception, spatial awareness and proprioception (body awareness).

Sensory inputs need to be appropriate to each child's ability [32], as well as to each child's individual preferences. Bombarding a child with multi-sensory stimuli will only create confusion and inhibit his/her learning. For that reason, in the development of the IROMEC robot attention was given to the possibility of being able to modulate the robot's sensory stimuli in terms of intensity, frequency, duration, complexity and novelty, according to each child's preferences and individualities.

For example, for some children with autism even the lowest noise can be very disturbing.

This domain targets the importance of developing awareness of the child's body image, its body as a whole, as well as the formation of concepts of laterality and directionality. For example, the scenario IS04 "Imitation" fosters sensory motor intelligence, proprioception (awareness of the body) and hand-eye coordination. A realistic body image and sense of personal space is important in relation to the organization of functional movement in relation to people, objects, and the immediate environment.

\section{B. Communication and interaction}

Basic communication skills are crucial for taking part in and enjoying interactions with others in everyday activities. For many young children with autism, however, learning to communicate is not an easy or a naturally occurring task.

Communication can be divided in the two broad domains of receptive and expressive communication. Receptive communication is the comprehension aspect of any exchange of ideas and is considered part of the cognitive domain, while expressive communication (from now on simply called "communication") is part of the communication and interaction developmental area.

In this developmental area, the improvements that a child can achieve by interacting with the IROMEC robot cover different communication modes that include non-verbal (such as gestures and pointing behaviour), verbal (as preverbal vocalization), and vocal communication (as the production of speech sound, such as monosyllabic speech as 'baaa' and non speech sound as laughs). For example, in the scenario IS04 "Make it move", one of the variations specifically targets children that have no language and fosters the development of non verbal speech sounds (i.e. speech sounds can be used to control the robot movements).

The communication and interaction domain encompasses also intentional communication, and speech development articulation (sound development), acknowledging the importance of the imitation process (verbal and non verbal) in children's development.

Other objectives of the interaction with the IROMEC robot in the communication and interaction developmental area are related to the improvement of basic interpersonal interaction and particular interpersonal relationships.

Basic interpersonal interaction skills are generally acquired from a very early age through our ongoing experience with the world and interactions with the people around us. Children with autism experience difficulties in this domain. Turn taking, taking initiative, proximity between peers, gaze shift, eye contact and response to others are elements that deserve special attention during the education process of children with autism. The IROMEC play scenarios focus on helping children to build these skills 
while they interact with the robot. For example, the scenario IS02 "Turn raking for sensory reward" fosters the initiation and the response during interaction while helping to maintain a close distance between peers while interacting. The robot's visual features were designed to create and increase the level of response to eye contact with others, thereby improving also the child's eye-gaze.

\section{Cognitive development}

Cognition is composed of mental processes by which individuals acquire knowledge and an understanding of their environment. The cognitive domain encompasses children's abilities to learn from past and novel experiences.

In the area of cognitive development the objectives that interacting with the IROMEC robot could help to reach are based on the following seven different aspects: global intellectual function, memory functions, higher-level cognitive functions, copying, attention functions, energy and drive functions and undertaking of task. Progress towards these objectives will enable the children to understand and cope better their environment.

Because children with autism may have deficiencies in both understanding cause and effect (global intellectual function) and in memory function, certain play scenarios with the IROMEC robot are designed to assist them in improving their memory and in understanding the connection or relationship between a cause and its effect or between regularly correlated phenomena. For example, both the scenarios IS01 "Turn taking" and IS02 "Sensory reward" foster cause and effect connection (e.g. press a button and as a reaction the robot moves/a light flash).

The interaction with the robot is also intended in a way to help children with autism to improve their control of the wish for or delay of gratification (higher-level cognitive function). For example, in the scenario IS02 "Sensory reward" where the activity consists of pressing buttons for sensory rewards, the child has to wait for and collaborate with the other player in order to reach the robot's final reward; the game is designed in such a way that the buttons have to be pressed in turns, otherwise nothing will happen (i.e. when the child keeps pressing his/her button).

Imitation plays a significant role in the development of social cognition, as it is an important tool used for transferring knowledge in social contexts. Imitation can serve not only as a learning tool to acquire new physical skills (like the usage of various objects) but also provides the foundation for learning about our social environment [3334]. Most of our human behaviours are learnt through observation and imitation of others. For children with autism, these processes do not occur naturally and need guidance in order to develop. The IROMEC robot's features can help these children in reproducing simple movements. For example, in the scenario IS03 "Imitation" during a triadic interaction involving a child, a robot, and a human, the robot can be used to engage the child in imitating arm and head movements of the human by reproducing the human's motions in a simplified way.

Children with autism show a lack of spontaneous sharing experiences with others. Attention functions and joint attention in particular are vital skills which affect the development of social interaction skills. The IROMEC robot's features can be used to promote the child in directing his/her attention toward the sources of stimuli (focusing attention) and in maintaining his/her attention, enabling him/her to become more selective about attention-giving in order to facilitate the development of discrimination.

The concept of joint attention is a bit more complicated than just following others' gaze, because it requires paying attention to the external world, to the actions of other people, and - at the same time - to their own actions. Initial trials with the IROMEC robot show that its features encourage recurring joint attention events, in which both the child and the other player focus on the same stimulus at the same time.

\section{Motor development}

Motor development includes all aspects of controlling the body, its muscles, and its movements. It is through movement that children respond to their environments.

For children with physical disabilities, there is an obvious and unambiguous need to promote motor development. Even children who have no physical limitations to their movements may have a very restricted and often stereotyped range of spontaneous movements which will limit their ability to interact with and learn from their surroundings.

In the area of motor development the objectives that the IROMEC robot targets for children with autism are based on the following four different aspects: mobility of the body, fine hand use, neuromusculoskelatal functions and psychomotor functions. Progress towards these aims will enable children to exercise some degree of control over their own environments and experiences.

The interaction with the IROMEC robot seeks to increase control of hand and arm movements (fine hand use and body mobility). For example, the scenario IS8 "Bring me the ball" fosters both gross body movement and promotes fine hand movements.

The body mobility focuses on two aspects: the improvement of coordination and balance and the development of gross motor skills. More specifically, gross motor skills are related to the ability of controlling movements of large muscles (e.g. arms, legs).

The fine hand use objective aims at improving children's fine coordination of hand movements (e.g. grasping). This component is linked with visual control in conjunction with hand and arm movements and eye-hand coordination, promoting psychomotor and neuromusculoskelatal functions.

Psychomotor function involves both motor and psychological components in order to improve the regulation 
of behavioural speed, response time, and the sequences of movement (motor planning), while neuromusculoskelatal functions aims at improving the control over and the coordination of simple voluntary movements.

\section{E. Social and emotional development}

This is a very broad area, concerned with children as individuals and as member of society. It encompasses those skills and characteristics which enable a child to become accepted in social situations and which encourage their emotional development.

The social-emotional domain is strictly interrelated with the previous ones, as it consists of the acquisition of capacities for human relationships, emotional expression, and engagement in play. It is based on the motivation to engage in positive interactions and sustain personal relationships.

Social development starts when a child gains awareness that they are a separate individual and has a concept of self and identity. Positive self-concept and self-esteem are very important traits. The embodiment aspect of the IROMEC robot and the play scenarios developed can assist children in improving the sense of agency, the sense of self and the awareness of one's own body and identity.

Children have to learn to mix and to communicate with others, to share things, take turns, and to live by the generally accepted rules which govern each community. The IROMEC robot can be used to assist the children in moving from onlooker play (the child simply observes the play actions of others but does not join their activities), or parallel play (the child plays with in the presence of others, but does not join their activities), to shared cooperative play, where the child join others in play activities with a common goal or purpose.

\section{CONCLUSION}

Play is important and necessary to stimulate and support the acquisition of abilities in cognitive, sensory, motor, communication, emotional and social developmental areas. Play is not only part of children's development, it is a tool for children's development and every child has the right to experience the joy of playing.

Robots have already been used to teach basic social interaction skills using turn-taking and imitation games [15, 35]. The educational and therapeutic value of the IROMEC robotic toy is the possibility to use one single toy to target different objectives in different developmental areas for children with a wide spectrum of disabilities (see table 1).

The IROMEC play scenarios provide a variety of experiences and possibilities for targeting different developmental objectives. For example, in the area of sensory development, the play scenario called 'Get in contact' fosters tactile and visuo-spatial perceptual functions. The play scenario called 'Make it move' fosters non verbal speech sounds in vocal communication in the developmental area of communication and interaction. Within the objectives in cognitive development, the play scenario 'Sensory reward' fosters cause and effect connections and attention skills. In the area of social and emotional development, the play scenario 'Imitation' promotes a sense of self and awareness of one's own body and identity.

\begin{tabular}{|c|c|}
\hline $\begin{array}{l}\text { Sensory } \\
\text { development }\end{array}$ & $\begin{array}{l}\text { - Various tactile surfaces } \\
\text { - Visual feedback } \\
\text {-Different colored lights } \\
\text {-Icons on the screens } \\
\text {-Animations on the screens } \\
\text { - Robot mobility } \\
\text { - Arms and head movement }\end{array}$ \\
\hline $\begin{array}{l}\text { Communication } \\
\text { and interaction }\end{array}$ & $\begin{array}{l}\text { - Sound recognition system } \\
\text { - Buttons and wireless switches } \\
\text { - Visual feedback } \\
\quad \text {-Different coloured lights } \\
\text {-Icons on the screens } \\
\text {-Animations on the screens } \\
\text { - Robot mobility } \\
\text { - Arms and head movement } \\
\text { - Implementation of turn-taking beahviours }\end{array}$ \\
\hline $\begin{array}{l}\text { Cognitive } \\
\text { development }\end{array}$ & $\begin{array}{l}\text { - Implementation of imitation behaviours } \\
\text { - User interface satisfying cause and effect activities } \\
\text { - Software controlling complexity of robot behaviour } \\
\text { - Build in mechanism for feedback control loop }\end{array}$ \\
\hline $\begin{array}{l}\text { Motor } \\
\text { development }\end{array}$ & $\begin{array}{l}\text { - Robot mobility } \\
\text { - Arms movement } \\
\text { - Buttons } \\
\end{array}$ \\
\hline $\begin{array}{l}\text { Social and } \\
\text { emotional } \\
\text { development }\end{array}$ & $\begin{array}{l}\text { - User interface managing collaborative play } \\
\text { - Facilitation of multi player activities }\end{array}$ \\
\hline
\end{tabular}

Being a programmable system, the robot can provide various stimuli that could promote the child to interact with it in different ways. The possibility to modify the responses of the robot according to the way a child interacts (e.g. different inputs) allows different children to participate in the game.

An additional value of the IROMEC robot is the inclusion factor. The robot has been developed to be used by children with autism as well as their peers, whether they have special needs or not. The robot can be used as an object of shared attention that can encourage interaction with peers and adults. Moreover, as a robotic system, IROMEC can gradually increase the complexity of the interaction by providing different stimuli that may promote further and different learning (e.g. a simple cause and effect game might become more complex turn-taking activity). The robot adapts itself and develops along with the child, helping him/her in exploring and reaching increasingly complex objectives needed for social interaction dynamics.

The IROMEC robot will soon be evaluated in interactions with children with autism. Results from these studies will be report in forthcoming publications.

\section{ACKNOWLEDGMENT}

The work described in this paper is conducted within the 
EU project IROMEC (Interactive Robotic Social Mediators as Companions) and is funded by the European Commission in the 6th Framework Program under contract IST-FP6045356. We would like to thank the IROMEC partners for their contribution in the development of the therapeutic and educational objectives for play scenarios with the IROMEC robot. We would also like to give special thanks to the teaching staff, parents and children at Woodland school, St. Elizabeth's School, and Middleton School.

\section{REFERENCES}

[1] www.iromec.org

[2] J.P. Piaget, Play, dreams, and imitation in childhood. Norton, New York ,1962.

[3] L. Vygotsky, Play and its role in the mental development of the child. Soviet Psychology, 1966, 12, pp. 6-18.

[4] D. Winnicott, Play and reality. Stockholm: Natur och Kultur, 1981.

[5] J.S. Bruner, The relevance of education. George Allen and Unwin Ltd, London, 1971.

[6] United Nations High Commissioner for Human Rights. Convention on the Rights of the Child. General Assembly Resolution 44/25 of 20 November 1989, article 31. Available at: http://www.unhchr.ch/html/menu3/b/k2crc.htm

[7] S. Besio, "Allowing Children with Motor Impairment to Play, Learn, Learn to Play: A new Biennial Research Project of SIVA", in Proc. 3rd AAATE Conf., Ljubljana, 2001, pp. 231-234.

[8] I. Werry, K. Dautenhahn, and W. Harwin, "Evaluating the response of children with autism to a robo" in: Simpson, R. (Eds.), RESNA, USA: Resna Press, Arlington, 2001, pp. 14-9.

[9] H. Kozima et al, "Children-robot interaction: A pilot study in autism therapy", in Prog. Brain Res, 2007, 164:385-400.

[10] C.E. Lathan, and S. Malley, "Development of a New Robotic Interface for Telerehabilitation", in Proc. 2001 EC/NSF workshop on Universal accessibility of ubiquitous computing. 2001, p 80-83.

[11] P. Marti, A. Rullo, H. H. Lund, and J. Nielsen, "Playing with emotions", in ECCE, York, UK, 2004.

[12] P. Marti, A. Pollini, A. Rullo, and T. Shibata, "Engaging with artificial pets", in EACE 2005.

[13] D. Stiehl, J. Lieberman, C. Breazeal, L. Basel, R. Cooper, and H. Knight, "The Huggable: A Therapeutic Robotic Companion for Relational, Affective Touch", in IEEE Consumer Communications and Networking Conf., Las Vegas, NV, USA, 2006.

[14] B. Robins, K. Dautenhahn, R. te Boekhorst, and A. Billard, "Effects of repeated exposure of a humanoid robot on children with autism," in Designing a More Inclusive World, S. Keates, J. Clarkson, P. Langdon, and P. Robinson, Eds. London: Springer- Verlag, 2004, pp. 225-236.

[15] B. Robins, P. Dickerson, P. Stribling, and K. Dautenhahn, "Robotmediated joint attention in children with autism: A case study in a robot human interaction," Interaction studies, 2004, 5, pp. 161-198.

[16] B. Robins, K. Dautenhahn, R. te Boekhorst, and A. Billard, "Robotic assistants in therapy and education of children with autism: Can a small humanoid robot help encourage social interaction skills?," in Universal Access in the Information Society, Springer-Verlag, 2005.

[17] F. Michaud, H. Larouche, F. Larose, T. Salter, A. Duquette, H. Mercier, M. Lauria, "Mobile robots engaging children in learning”, in Canadian Medical and Biological Engineering Conf., Toronto, 2007.

[18] B. Robins, K. Dautenhahn, P. Dickerson, "From Isolation to Communication: A Case Study Evaluation of Robot Assisted Play for Children with Autism with a Minimally Expressive Humanoid Robot”, Proc. Second Inter. Conf. Advances in CHI, ACHI09, 2009.

[19] E. Fombonne, Epidemiology of pervasive developmental disorders. Pediatr Res, 2009.

[20] DSM-IV-R, Diagnostic and Statistical Manual of Mental Disorders. American Psychiatric Association, 2000

[21] R. Jordan, Autistic Spectrum Disorders - An Introductory Handbook for Practitioners. London: David Fulton Publishers, 1999.
[22] S. Baron-Cohen, Mindblindness: An Essay on Autism and Theory of Mind. MIT Press, USA, 1995.

[23] G. Gillingham, Autism: Handle with Care: Understanding and Managing Behaviour of Children and Adults with Autism. Arlington: TX. Future Education Inc, 1995.

[24] D. Garon, R. Filion, and M. Doucet, El sistema ESAR: Un método de análisis psicológico de los juguetes. Alicante, Spain, 1996.

[25] B. Robins, E. Ferrari, and K. Dautenhahn, "Developing Scenarios for Robot Assisted Play”, in Proc. 17th International Symposium on Robot and Human Interactive Communication RO-MAN2008, 2008, pp. $180-186$.

[26] B. Robins, E. Ferrari et all. "A Case Study in Human-centred Design Methods: Developing Scenarios for Robot Assisted Play Informed by User Panels and Field Trials" submitted to journal

[27] J.M. Carroll, Scenario-based Design: Envisioning Work and Technology in System Development. New York: Wiley, 1995.

[28] M.B. Rosson and J. M. Carroll, "Scenario-Based Design," in The Human-Computer Interaction Handbook: Fundamentals, Evolving Technologies and Emerging Applications, v. 53, J.Jacko and A. Sears, Eds.: Lawrence Erlbaum Associates, 2002, pp. 1032-1050.

[29] A. Rozzo, P. Marti, F. Decortis, C. Moderini, and J. Rutgers, "The Design of POGO Story World,” in E. Hollnagel (ed.) Cognitive Task Design. London: Earlbaum, 2003.

[30] WHO, International Classification of Functioning, Disability and Health. Geneva: World Health Organization, 2001.

[31] C. Tilstone and L. Layton, Child development and teaching pupils with special needs. Routledge Falmer, 2004.

[32] T.G.R. Bower, A primer of infant development. Oxford: W. H. Freeman, 1977.

[33] J. Nadel, C. Guérini, and A. Pezé, "The evolving nature of imitation as a format of communication". In J. Nadel. G. Butterworth, Eds., Imitation in Infancy, Cambridge University Press, 1999, pp. 209-234.

[34] K. Dautenhahn and I. Werry, "Towards interactive robots in autism therapy: background, motivation and challenges." Pragmatics and Cognition, 2004, 12, 1, pp. 1-35.

[35] K. Dautenhahn, "Robots as social actors: Aurora and the case of autism”, in: Proc. International Cognitive Technology Conf., 1999, 359-374.

[36] P. Marti, C. Moderini, L. Giusti, A. Pollini, “A Robotic Toy for Children with special needs: From requirements to Design" in Proc. IEEE 11th International Conference on Rehabilitation Robotics ICORR 2009 pp. 918-923

[37] B. Robins, N. Otero, E. Ferrari, K. Dautenhahn, "Eliciting Requirements for a Robotic Toy for Children with Autism - Results from User Panels", in Proc.16th International Symposium on Robot and Human Interactive Communication RO-MAN 2007, 2007, pp. 101-106.

[38] G. J. Gelderblom, J. Dijkstra, G. Kronreif, "User Involvement in IROMEC: Robot Development for Children with Disabilities", in Proc. AAATE07, 2007, pp. 515-519 